University of New Hampshire

University of New Hampshire Scholars' Repository

Psychology Scholarship

College of Liberal Arts (COLA)

$9-1-2008$

\title{
Emotional intelligence: New ability or eclectic traits?
}

John D. Mayer

University of New Hampshire, Durham, jack.mayer@unh.edu

Peter Salovey

Yale University

David R. Caruso

Yale University

Follow this and additional works at: https://scholars.unh.edu/psych_facpub

Comments

(CAPA, 2008. This paper is not the copy of record and may not exactly replicate the authoritative document published in the APA journal. Please do not copy or cite without author's permission. The final article is available, upon publication, at: https://dx.doi.org/10.1037/0003-066X.63.6.503

\section{Recommended Citation}

Mayer, J. D., Salovey, P., \& Caruso, D. R. (2008a). Emotional intelligence: New ability or eclectic traits? American Psychologist, 63, 503-517.

This Article is brought to you for free and open access by the College of Liberal Arts (COLA) at University of New Hampshire Scholars' Repository. It has been accepted for inclusion in Psychology Scholarship by an authorized administrator of University of New Hampshire Scholars' Repository. For more information, please contact Scholarly.Communication@unh.edu. 
RUNNING HEAD: EMOTIONAL INTELLIGENCE

\title{
Emotional Intelligence: New Ability or Eclectic Traits?
}

\author{
John D. Mayer \\ University of New Hampshire \\ Peter Salovey \\ David R. Caruso \\ Yale University
}

\section{Prepublication version of:}

Mayer, J. D., Salovey, P., \& Caruso, D. R. (2008). Emotional intelligence: New ability or eclectic traits? American Psychologist, 63, 503-517.

\section{Author Notes}

The authors gratefully acknowledge the comments of Marc A. Brackett and Susan E. Rivers, as well as the contributions of several anonymous reviewers, all of whom commented on drafts of this manuscript.

Disclosure: John D. Mayer, Peter Salovey, and David R. Caruso receive royalties from the Mayer-Salovey-Caruso Emotional Intelligence Test, which is published by Multi-Health Systems (MHS), Toronto, Canada.

Correspondence concerning this article should be addressed to John D. Mayer, Department of Psychology, 10 Library Way, University of New Hampshire, Durham, NH 03824. E-mail: jack.mayer@unh.edu. 


\begin{abstract}
Some individuals have a greater capacity than others to carry out sophisticated information processing about emotions and emotion-relevant stimuli, and to use this information as a guide to thinking and behavior. We have termed this set of abilities emotional intelligence (EI). Since the introduction of the concept, however, a schism has developed in which some researchers focus on EI as a distinct group of mental abilities, and other researchers instead study an eclectic mix of positive traits such as happiness, self-esteem, and optimism. Clarifying what emotional intelligence is and is not can help the field by better distinguishing research that is truly pertinent to emotional intelligence from what is not. Emotional intelligence conceptualized as an ability - is an important variable both conceptually and empirically, and it shows incremental validity for predicting socially-relevant outcomes.
\end{abstract}

KEYWORDS: Emotion, intelligence, emotional intelligence, personality, measurement 


\section{Emotional Intelligence: New Ability or Eclectic Traits?}

The notion that there is an emotional intelligence (EI) began as a tentative proposal (Mayer, DiPaolo, \& Salovey, 1990; Salovey \& Mayer, 1990). The original idea was that some individuals possess the ability to reason about and use emotions to enhance thought more effectively than others. Since 1990, EI has grown into a small industry of publication, testing, education, and consulting (Matthews, Roberts, \& Zeidner, 2004; Matthews, Zeidner, \& Roberts, 2002). Matthews et al. (2002) have outlined the dramatic growth of the psychological literature concerning an emotional intelligence. Yet the apparent size of the field dwarfs what we regard as relevant scientific research in the area. In fact, one commentator recently argued that emotional intelligence is an invalid concept, in part because it is defined in too many ways (Locke, 2005, p. 425).

The original definition of emotional intelligence conceptualized it as a set of interrelated abilities (Mayer \& Salovey, 1997; Salovey \& Mayer, 1990). Yet, other investigators describe emotional intelligence as an eclectic mix of traits, many dispositional, such as happiness, selfesteem, optimism, and self-management rather than ability-based (Bar-On, 2004; Boyatzis \& Sala, 2004; Petrides \& Furnham, 2001; Tett, Fox, \& Wang, 2005). This alternative approach to the concept - the use of the term to designate eclectic mixes of traits - has led to considerable confusion and misunderstandings as to what an emotional intelligence is, or should be (Daus \& Ashkanasy, 2003; Gohm, 2004; Mayer, 2006). Many features, such as self-esteem, included in these models do not directly concern emotion or intelligence or their intersection (Matthews et al., 2004, p. 185). We agree with many of our colleagues who have noted that the term emotional intelligence is now employed to cover too many things - too many different traits; too many different concepts (Landy, 2005; Murphy \& Sideman, 2006; Zeidner, Roberts, \& Matthews, 2004). “These models," wrote Daus and Ashkanasy (2003, pp. 69-70) "have done more harm than good regarding establishing emotional intelligence as a legitimate, empirical construct with incremental validity potential." This article explores those key criticisms of the field, contrasting what we believe to be a meaningful theory of emotional intelligence with models describing it as a mix of traits.

Our principal claim is that a valid EI concept can be distinguished from other approaches. This valid conception of emotional intelligence includes the ability to engage in sophisticated information processing about one's own and others' emotions, and then to use this information as a guide to thinking and behavior. That is, individuals high in EI pay attention to, use, understand, and manage feelings, and these skills serve adaptive functions that potentially benefit themselves and others (Mayer, Salovey, \& Caruso, 2004; Salovey \& Grewal, 2005). As we use the term, emotional intelligence is an instance of a standard intelligence that can enrich the discussion of human capacities (Mayer, Salovey, Caruso, \& Sitarenios, 2001).

The deeper question raised by Locke (2005) and others' assertions that emotional intelligence has become over-general is: "How does one decide something ought or ought not to be called emotional intelligence?" To address this, the first section of this article, "The Schism in the Field" examines the central conception of EI and how the current confusion in the field grew. The second section, "The Four Branch Model of Emotional Intelligence," further describes our approach to emotional intelligence. The third section, "The Significance of Emotional Intelligence," examines the various reasons that emotional intelligence is important as a discrete variable. Finally, in the "Discussion and Recommendations" section, consideration is 
given to how the term emotional intelligence has come to be so misused and the steps that can be taken to improve terminology and research in the area.

\section{THE SCHISM IN THE FIELD}

Initial Ideas

Our initial view of emotional intelligence was that it consists of a group of related mental abilities. For example, we first defined EI as a "the ability to monitor one's own and others' feelings and emotions, to discriminate among them and to use this information to guide one's thinking and actions" (Salovey \& Mayer, 1990, p. 189). An empirical companion piece operationalized aspects of EI as an ability: participants examined a set of colors, faces, and designs, and, for each, had to identify its emotional content (Mayer et al., 1990). In a subsequent editorial in the journal Intelligence, we discussed the difference between traits such as extraversion, self-confidence and EI, noting:

...Although a trait such as extraversion may depend on social skill, or result in it, [it] is a...preference rather than an ability. Knowing what another person feels, in contrast, is a mental ability. Such knowledge may stem from $g$, or be somewhat independent of it. The way in which we have defined emotional intelligence - as involving a series of mental abilities - qualifies it as a form of intelligence (Mayer \& Salovey, 1993, p. 435).

Although we were clear about our ability conception, we acknowledge that our earliest model was, in some of its specifics, overly broad. That model, for example, included flexible planning and creative thinking as two skills involved in utilizing emotions (Salovey \& Mayer, 1990, p. 190). Subsequent interpreters of our work, however, were instrumental to (what we regard as) unmooring the concept from its key terms. Those interpreters appear to have confused what we thought of as expressions of emotional intelligence, with the ability itself. For example, we suggested that the emotionally intelligent person might be "a pleasure to be around," and that those lacking in EI might be prone to depression (Salovey \& Mayer, 1990, p. 201) Elsewhere in those early writings, we noted EI might be related to openness (Mayer \& Salovey, 1993, p. 438).

\section{External Factors}

A journalistic rendering of emotional intelligence created and also complicated the popular understanding of it. Goleman's (1995) best-selling book, Emotional Intelligence, began with the early version of our EI model but mixed in many other personality traits including persistence, zeal, self-control, character as a whole, and other positive attributes. The book received extensive coverage in the press, including a cover story in Time magazine (Gibbs, 1995, October 2). Because the book included, in part, the theory we developed, some investigators wrongly believed that we endorsed this complex and, at times, haphazard composite of attributes as an interpretation of emotional intelligence.

The journalistic version became the public face of EI, and attracted further attention, in part, perhaps, owing to its extraordinary claims. Goleman (1995, p. 34) wrote of EI's importance that "...what data exist, suggest it can be as powerful, and at times more powerful, than IQ." A few years later, Goleman remarked (1998a, p. 94) that "nearly $90 \%$ of the difference" between star performers at work and average ones was due to EI. Although these ideas appeared in trade books and articles, they were widely disseminated and influenced scientific articles as well. For example, one refereed journal article noted that "EI accounts for over $85 \%$ of outstanding performance in top leaders" and "EI - not IQ - predicts top performance" (Watkin, 2000, p. 89). 
Our own work never made such claims, and we actively critiqued them (Mayer, 1999; Mayer \& Cobb, 2000; Mayer \& Salovey, 1997; Mayer, Salovey, \& Caruso, 2000). More recently, Goleman wrote that others who believed that EI predicts huge proportions of success had misunderstood his 1995 book (Goleman, 2005, p. xiii).

The Advent of Mixed Models

With EI defined in the public mind as a variety of positive attributes, further approaches continued to expand the concept. One defined EI quite broadly as, "an array of noncognitive capabilities, competencies, and skills that influence one's ability to succeed in coping with environmental demands and pressures" (Bar-On, 1997, p. 14). Although the model included emotion-related qualities such as emotional self-awareness and empathy, into the mix were added many additional qualities including reality testing, assertiveness, self-regard, and selfactualization. It was this mixing in of related and unrelated attributes that led us to call these mixed models of EI (Mayer, Salovey, \& Caruso, 2000). A second mixed model of EI included such qualities as trustworthiness, adaptability, innovation, communication, and team capabilities as emotional competencies (Goleman, 1998b). The additions of this model led to the characterization of such an approach as "preposterously all-encompassing" (Locke, 2005, p. 428).

Still another research team defined a trait EI as referring to: .... constellation of behavioral dispositions and self-perceptions concerning one's ability to recognize, process, and utilize emotion-laden information. It encompasses...empathy, impulsivity, and assertiveness as well as elements of social intelligence... and personal intelligence... (Petrides \& Furnham, 2003, p. 278)

At this point, the pattern is clear: A large number of personality traits are amassed, mixed in with a few socio-emotional abilities, and the model is called one of emotional intelligence or trait emotional intelligence. (The "trait" designation is particularly confusing, as trait is typically defined as a distinguishing quality, or an inherited characteristic, and could apply to any EI model). Generally speaking, these models include little or no discussion of why certain traits are included and others are not, or why, for that matter, certain emotional abilities are included and others are not, except for an occasional mention that the attributes are chosen because they are most likely to predict success (e.g., Bar-On, 1997).

Such approaches are disappointing from a theoretical and construct validity standpoint, and they are scientifically challenging in that, with so many independent qualities, it is hard to identify a global theme to these lists of attributes. There is, however, an alternative to such a state of (what we see as) disorganization. We believe that our four-branch model of emotional intelligence, for example, provides one conceptually coherent approach (Mayer \& Salovey, 1997). It is to this model that we turn next.

\section{THE FOUR-BRANCH MODEL OF EMOTIONAL INTELLIGENCE}

\section{General Introduction to Emotional Intelligence Intelligence Considered}

It is possible to develop a coherent approach to the concept of emotional intelligence. In order to describe an emotional intelligence, we need first to define intelligence. Debates have raged from the beginning of intelligence theorizing and testing regarding the nature of intelligence, and also, how many intelligences exist (Neisser et al., 1996). However, even the 
fiercest of ' $g$ ' theorists, those proposing that intelligence is best described as consisting of a single, general mental ability factor, allow for the existence of more specific ability factors (e.g., Carroll, 1993).

Intelligences can be divided up in different ways, for example, according to whether they address crystallized (memory-dependent) or fluid (process-dependent) abilities, or, alternatively, according to the type of information that is their focus. The approach that divides intelligences into information areas, for example, yields a verbal-propositional intelligence that deals with words and logic, and a spatial intelligence that deals with arranging and rotating objects in space, among others. Analogously, an emotional intelligence would address (a) the capacity to reason with and about emotions, and/or (b) the contribution of the emotions system to enhance intelligence.

One longstanding grouping of intelligences divides them into verbal/propositional and perceptual organizational areas (e.g., Kaufman, 2000). For decades, researchers have searched for an elusive third intelligence, believing that these two core intelligences were insufficient to describe individual differences in mental abilities by themselves (Walker \& Foley, 1973; Wechsler, 1943). In 1920, Thorndike (1920, p. 228) suggested the existence of a social intelligence, which involved "the ability to understand and manage men and women, boys and girls - to act wisely in human relations" (see also, Bureau of Personnel Administration, 1930; Thorndike \& Stein, 1937). Social intelligence began to be investigated, although it had vocal critics - whose criticisms may have impeded the field's growth (Cronbach, 1960).

None of the proposed earlier intelligences, however, explicitly concerned an emotional intelligence - reasoning validly about emotions and then using emotions in the reasoning process. By the early 1980's, there was a greater openness to the idea of specific (or multiple) intelligences (Gardner, 1983; Guilford, 1959; Sternberg, 1985), and at the same time, research in emotions was blossoming. Ekman (1973) and others had resurrected Darwin's ideas that some emotional information - for example, human facial expressions of certain emotions - are universal; others examined how events lead to cognitive appraisals that in turn generate emotions (Dyer, 1983; Roseman, 1984; Scherer, 1993; Sloman \& Croucher, 1981; Smith \& Ellsworth, 1985).

Perhaps the elusive intelligence that could complement the traditional dichotomy of verbal/propositional and perceptual/organizational might be one of emotional intelligence. An emotional intelligence, after all, when compared to social intelligence, arguably could have a more distinct brain locus in the limbic system and its cortical projections (Damasio, 1994; LeDoux, 2000; MacLean, 1973; TenHouten, Hoppe, Bogen, \& Walter, 1985). An initial theory of emotional intelligence developed these ideas, along with a first demonstration study to indicate how aspects of it might be measured (Mayer et al., 1990; Salovey \& Mayer, 1990).

\section{Emotions as Signals}

To describe convincingly what it means to reason with emotions, however, one must understand their informational content. Initially, some people express surprise that emotions convey information at all. Emotions often are viewed as irrational, will o' the wisp states - even pathological in their arbitrariness (Young, 1943). Although this does describe the operation of emotion at times, it is far from a complete picture of a normal, functioning emotion system.

The meanings of specific emotion terms have been understood by philosophers for hundreds of years (Solomon, 2000) and have been refined by psychologists (Clore, Ortony, \& Foss, 1987; Frijda, 1988; Ortony, Clore, \& Collins, 1988; Roseman, 1984; Smith \& Ellsworth, 1985). For example, happiness includes a signal of wanting to join with others; sadness is a 
signal of loss, and of wanting comfort (or to be alone). Until recently, however, the significance of these terms was not always recognized. William James, for example, wrote that he would rather "...read verbal descriptions of the shapes of the rocks on my New Hampshire farm..." than a catalogue of emotional meanings (James, 1892/1920, p. 375).

Such viewpoints began to change as the emotion system became viewed increasingly as an evolved signaling system (Darwin, 1872/1998; Ekman, 1973). To be sure, some differences exist in expressing and reading emotions across cultures (Ekman, 1973; Elfenbein \& Ambady, 2002a; Mesquita, 2001). At the same time, there is compelling evidence that many emotion meanings are in large part universal - and play a key role in helping people to understand their own and others' actions (e.g., Dyer, 1983; Ekman, 1973).

By the 1990's, the significance of emotions and their meanings were better appreciated and were increasingly studied empirically. The functional role of emotions as communication signals became widely accepted, although further issues remain to be explored such as the meanings of affective dimensions and how social influences may modify emotional expression (Averill, 1992; Barrett \& Russell, 1999). Prominent undergraduate textbooks on emotion and research handbooks appeared (e.g., Carlson \& Hatfield, 1992; Lazarus, 1991; Lewis \& HavilandJones, 2000; Oatley \& Jenkins, 1996; Strongman, 1996). Curricula designed expressly to teach emotional knowledge and literacy in the schools also have been developed (Brackett et al., 2007; Maurer \& Brackett, 2004; Wilson, 2007).

\section{Emotional Intelligence and the}

\section{Four-Branch Model}

Emotional abilities can be thought of as falling along a continuum from those that are relatively lower-level, in the sense of carrying out fundamental, discrete psychological functions, to those that are more developmentally complex and operate in the service of personal selfmanagement and goals. Crucial among lower-level, fundamental skills is the capacity to perceive emotions accurately. Higher-level skills include, for example, the capacity to manage emotions properly. These skills can be arranged in a rough hierarchy of four branches (these branches refer to a tree-like diagram; Mayer \& Salovey, 1997). These include the abilities to (a) perceive emotions in oneself and others accurately, (b) use emotions to facilitate thinking, (c) understand emotions, emotional language, and the signals conveyed by emotions, and (d) manage emotions so as to attain specific goals (Mayer \& Salovey, 1997). These four branches are illustrated in Figure 1.

As an example, imagine a situation in which a young man visits a friend in the hospital who has been in a car accident. The first area of emotional intelligence involves perceiving emotions. As the young man surveys the hospital room, the visiting relatives, and his unconscious friend, he may wonder, "What is each family member feeling?" Perhaps he perceives the worry and anxiety in their faces. Feelings are complex; also emerging from within him may be fear of his own mortality, and a guilty relief - with a surge in energy - in response to being spared the accident himself and remaining unharmed.

The anxiety experienced by those around the young man redirects his attention from his own concerns to a focus on the well-being of his friend. Using energy from the fear and relief, he may feel motivated to talk with family members and find out how they are. This is an example of using emotion to facilitate thought.

To understand the emotions of the situation involves asking, "What sorts of feelings emerge from such a situation?" and "How can these feelings be expected to change over time?" The accident is unexpected and severe, so the family's shock is palpable. The young man may 
reason that one feature of such shock is its emergence from a rapid combination of surprise, sadness, and other mostly negative emotions (Goodrum, 2005).

Knowing this, and understanding the feelings, one possible course would be to engage in emotion management. After regulating his own emotions, perhaps by observing them, and thereby psychologically distancing himself from them, the young person may inquire of the parents how they came to learn of the accident and how they are holding up, what their days are like, and how he can be of assistance. Listening creates a caring environment while helping to clarify the disturbing, ongoing events.

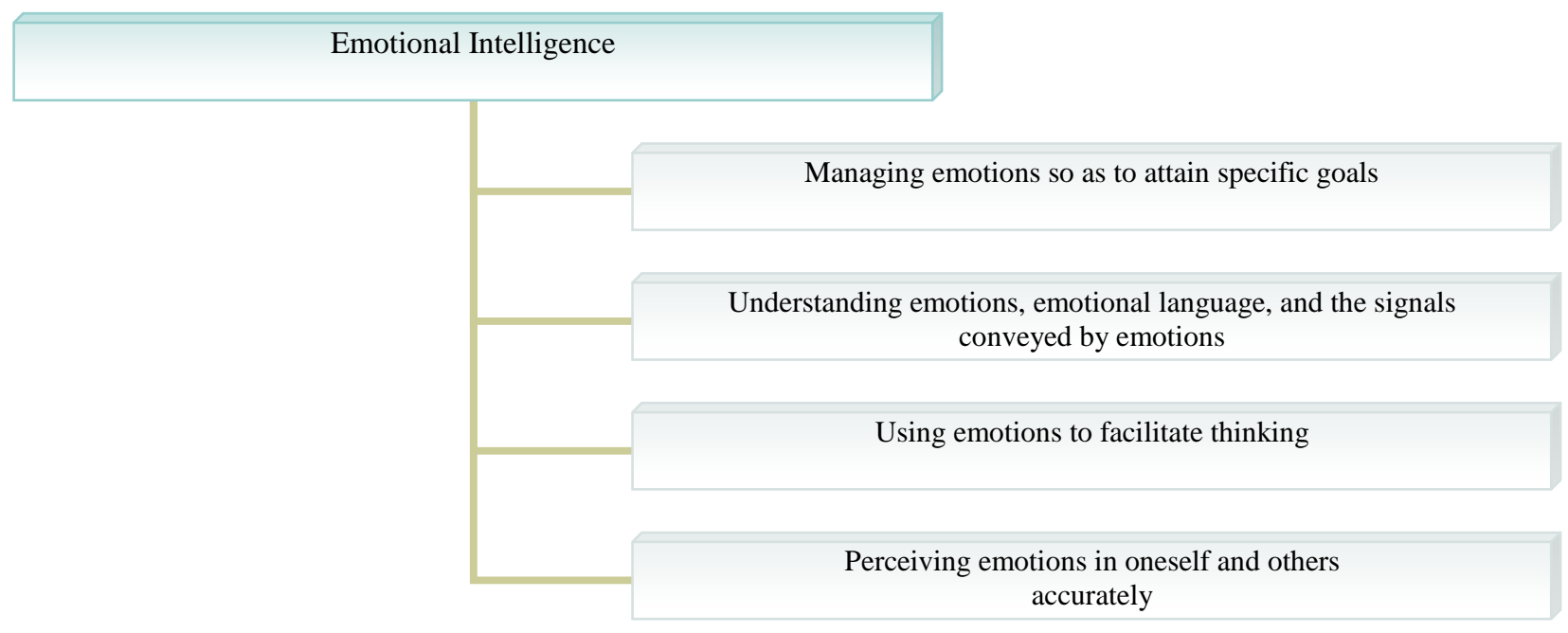

Figure 1. The Four-Branch Model of emotional intelligence (after Mayer \& Salovey, 1997). Each branch describes a set of skills that make up overall emotional intelligence. Each branch has its own developmental trajectory, proceeding from relatively easy skills to more sophisticated ones. For example, Perceiving Emotions typically begins with the ability to perceive basic emotions in faces and voice tones, and may progress to the accurate perception of emotional blends, and the detection of emotional micro-expressions in the face.

\section{Measuring Emotional Intelligence Ability Measures of Emotional Intelligence}

Individual differences exist in each of these four processes. For example, some people are more accurate in initially perceiving how each individual in this story might be feeling, recognizing their feelings from faces and postures. Such individual differences can be measured. Each ability area of our four-branch model of EI can be operationalized formally as a set of tobe-solved problems, and test-taker's responses can be checked against a criterion of correctness. There are a number of ability-based scales of emotional perception (Archer, Costanzo, \& Akert, 2001; Matsumoto, LeRoux, \& Wilson-Cohn, 2000), emotional identification and understanding (Geher, Warner, \& Brown, 2001), and of emotional integrative complexity (Lane, Quinlan, Schwartz, Walker, \& Zeitlin, 1990). 
One measure that spans these areas is the Mayer-Salovey-Caruso Emotional Intelligence Test (MSCEIT). It consists of eight tasks, two for each of the four branches of our EI model (Mayer, Caruso, \& Salovey, 1999; Mayer, Salovey, \& Caruso, 2002; Mayer, Salovey, Caruso, \& Sitarenios, 2003). For example, "Perceiving Emotions" is assessed by asking participants to identify emotions in pictures of faces, in one task, and in photographs and artwork, in another. As another example, one of the "Understanding Emotions" tasks employs items such as the following to gauge the capacity to reason with emotions:

What feeling, when intensified and coupled with a sense of injustice, is most likely to lead a person to experience anger?
a. frustration
b. guilt
c. melancholy
d. fatigue

Responses on the MSCEIT are scored with respect to their degree of correctness, as determined by their correspondence with the answers provided by a group of emotions experts (i.e., emotion researchers) or a normative sample of the general population. The best answer to the sample question above is: "a. frustration," because, intensified, it leads to anger. This approach to scoring is somewhat similar to that used for certain subtests of classic intelligence tests such as Comprehension on the Wechsler Adult Intelligence Scale (Matarazzo, 1972; Wechsler, 1997). Criticisms of this scoring procedure also have been raised and explored, and will be discussed in the next section.

Theory of the Measurement of Emotional Intelligence

There are two powerful theoretical reasons why only such a clearly focused, ability-based approach can best measure emotional intelligence. First, intelligences most generally are defined as mental abilities, and measuring mental abilities involves asking test-takers relevant questions and then evaluating their answers against a criterion of correctness (e.g., Carroll, 1993). The MSCEIT expert scoring system identified correct answers by using the pooled responses of 21 emotions researchers (Mayer et al., 2003).

In addition, according to the Standards of Educational and Psychological Testing, validity evidence is partly based on response processes. That is, "Theoretical... analyses of the response processes of test takers can provide evidence concerning the fit between the construct and the detailed nature of performance or response..." (Joint Committee on Standards, 1999, p. 12; see also Ployhart, 2006). Requiring test-takers to meet a criterion of correctness provides an excellent fit to the emotional intelligence concept. Incisive criticism in the area has promoted the progression from an early reliance on the consensus of test-takers as a criterion to the use of emotions experts (e.g., Roberts, Zeidner, \& Matthews, 2001). The two approaches to scoringexpert and general consensus - correlate highly with each other (Mayer et al., 2003). However, there is further room for refinement of such criteria, including the development of a veridical scoring system for many emotional intelligence test items.

Mixed models of emotional intelligence, recall, are those that mix in many attributes such as self-esteem and optimism, into the ability model. These approaches typically measure EI through self-judgments, using items of the form, "I understand my emotions well" (True/False). Such items draw information that is filtered through the self-concept of the test-taker. Testtakers, however, may or may not be able to understand the question, may or may not have received accurate feedback regarding the accuracy of their emotional perceptions before, and 
may, in their self-evaluations, be influenced by mood and tendencies toward selfaggrandizement. In direct tests, self-judgment-based response processes are not highly correlated with measured abilities of perceiving, using, understanding, and/or managing emotions (Brackett, Rivers, Shiffman, Lerner, \& Salovey, 2006).

In addition, because mixed model tests often include EI-irrelevant variables such as need for achievement and self-esteem, they assess the wrong concepts. Including other variables increases the degree of construct-irrelevant variance, which, as it rises, progressively invalidates a test (Joint Committee on Standards, 1999). For example, test makers who add commonlystudied personality traits (e.g., assertiveness, optimism) to their scales end up measuring classically-defined personality traits rather than emotional intelligence. Naming such a test "emotional intelligence" does not clarify this situation.

A test that focuses specifically on constructs relevant to EI, and evaluates responses as to their correctness possesses good evidence for its validity. A priori, it stands a much greater likelihood to measure the concept successfully. This is a strictly conceptual issue. Nonetheless, there is substantial empirical evidence, as well, that ability tests such as the MSCEIT measure emotional intelligence rather than other constructs, whereas other scales possess considerable construct-irrelevant variance - most specifically, an overlap with personality traits such as Neuroticism, Extraversion, and Conscientiousness (Brackett \& Mayer, 2003; Newsome, Day, \& Catano, 2000).

\section{Key Findings Concerning Emotional Intelligence and Other Psychological Traits}

If, as we claim, EI involves a unique source of variation that reflects a new intelligence, then it should exhibit some overlap with other intelligence scales. Studies indicate that EI, measured by the MSCEIT and its precursor test the MEIS, correlates about $r=.35$ or so with verbal intelligence, and lower with perceptual-organizational IQ (Ciarrochi, Chan, \& Caputi, 2000; Mayer et al., 1999). Most of the overlap with verbal intelligence is accounted for by the third branch of the MSCEIT, Understanding Emotions.

EI also should be relatively independent of more traditional personality scales. To test this, scales of EI can be correlated with the Big Five personality traits. The Big Five traits are Extraversion-Introversion, Neuroticism-Stability, Openness-Closedness, AgreeablenessDisagreeableness, and Conscientiousness-Carelessness. Each of the Big Five traits can be divided into more specific traits. For example, one approach to the Big Five divides Extraversion-Introversion into such facets as gregariousness, assertiveness, and warmth (Costa \& McCrae, 1992). The Big Five represents a good starting point for frequently studied personality dimensions, although some traits arguably are not measured by the Big Five (e.g., educateduneducated, diplomatic-humorous, religious-unreligious; Saucier \& Goldberg, 1998).

EI, defined here as an ability, should have minimal correlations with Big Five traits such as Extraversion or Neuroticism: whether people are sociable or emotional, they can be smart about emotions. We did predict that EI would have a modest relation to Openness, as Openness often correlates with intelligences (Mayer \& Salovey, 1993). Some representative correlations between the MSCEIT and the Big Five are shown in the first row of Table 1; the scale correlated $r=.25$ with Openness, and $r=.28$ with Agreeableness, a trait which includes empathic and interpersonally sensitive content, and had lower correlations with the rest (Brackett \& Mayer, 2003).

In contrast, mixed-model self-judgment scales labeled "emotional intelligence" appear to measure many variables that are relevant to motivations, social skills, and other areas of 
personality but not necessarily to an emotional intelligence (Brackett \& Mayer, 2003). Although variables such as optimism, self-control, and the like each have specific and uniquely important variance, as one measures many such traits together, they begin to reflect broader, more general traits of the sort found on the Big Five.

The relations of several mixed-model scales to the NEO-PI-R (Costa \& McCrae, 1992), a measure of the Big Five personality traits, are illustrated in the next rows of Table 1. Notably, mixed model EI scales correlate $r=-.57$ and -.70 with Neuroticism in two instances, and $r=.47$ and .65 with Extraversion in two others; their relations are somewhat lower to Openness or even Agreeableness. The overlap between mixed-model measures of EI and the NEO-PI-R becomes more striking when it is put into context. Consider a test explicitly designed to be parallel to the NEO-PI-R - the Big Five Inventory (Gosling, Rentfrow, \& Swann, 2003). The Big Five Inventory's correlations with the NEO-PI-R (Table 1, bottom row) are no higher than many of the correlations exhibited by the mixed model EI scales. That is, the mixed model EI scales overlap with the Big Five, sometimes as much as scales explicitly designed to measure the Big Five overlap with each other. The mixed-model scales drop off in prediction for traits such as Openness and Agreeableness, which arguably are most likely to be related to EI. Overall, the MSCEIT shows the greatest independence from the Big Five. The mixed-model scales' high overlap, and their pattern of overlap, with the Big Five indicates that for such mixed-model measures, construct-irrelevant variance predominates.

Table 1: Several Relevant Tests Ordered According to their Correlation with the NEO-PI-R measure of the Big Five

\begin{tabular}{|c|c|c|c|c|c|}
\hline & \multicolumn{5}{|c|}{ The Big Five } \\
\hline & Neuroticism & $\begin{array}{l}\text { Extra- } \\
\text { version }\end{array}$ & Openness & $\begin{array}{l}\text { Agreeable- } \\
\text { ness }\end{array}$ & $\begin{array}{l}\text { Conscien- } \\
\text { tiousness }\end{array}$ \\
\hline \multicolumn{6}{|c|}{ Emotional Intelligence (as Ability) } \\
\hline $\begin{array}{l}\text { Mayer-Salovey-Caruso Emotional } \\
\text { Intelligence Test: Total EI }\end{array}$ & $-.08 * *$ & $.11 *$ & $.25 * * *$ & $.28 * * *$ & .03 \\
\hline \multicolumn{6}{|c|}{ Mixed Model, Self-Judgment Scales } \\
\hline $\begin{array}{l}\text { Self-Report Emotional Intelligence } \\
\text { Test: Overall } E I^{\mathrm{a}}\end{array}$ & $-.19 * *$ & $.32 * * *$ & $.43 * * *$ & .09 & $.25 * * *$ \\
\hline $\begin{array}{l}\text { Emotional Competence Inventory: } \\
\text { Self-Awareness Cluster }\end{array}$ & -.07 & $.47 * *$ & $.28 * *$ & .00 & $.30 * *$ \\
\hline $\begin{array}{l}\text { Bar-On Emotional Quotient } \\
\text { Inventory: Overall } E Q^{\mathrm{a}} \\
\end{array}$ & $-.57 * * *$ & $.37 * * *$ & $.16^{*}$ & $.27 * * *$ & $.48 * * *$ \\
\hline $\begin{array}{l}\text { Trait Emotional Intelligence } \\
\text { Questionnaire (TEIQue): Overall } \\
E I^{\mathrm{c}}\end{array}$ & $-.70 * * *$ & $.65 * *$ & $.44 * *$ & -.04 & $.34 * *$ \\
\hline \multicolumn{6}{|c|}{ Big Five Subscales With Each Other (as a Comparison) } \\
\hline $\begin{array}{l}\text { Big Five Inventory }{ }^{\mathrm{d}} \text { Extraversion } \\
\text { with extraversion; } \text { neuroticism } \\
\text { with neuroticism, etc. }\end{array}$ & $.66 * * *$ & $.76^{* * *}$ & $.68 * * *$ & $.66 * * *$ & $.70 * * *$ \\
\hline \multicolumn{6}{|c|}{$\begin{array}{l}\text { a. Results from (Brackett \& Mayer, 2003); higher correlations between the Bar-On EQ-i and the NEO-FFI have been reported } \\
\text { (Dawda \& Hart, 2000, p. 807); } \\
\text { b. Correlations from (Boyatzis \& Sala, 2004; Murensky, 2000); only cluster-level results are reported. } \\
\text { c. Correlations from Petrides \& Furnham (2003). } \\
\text { d. An alternative measure of the Big Five traits correlated with the NEO-PI; results from (Gosling et al., 2003). }\end{array}$} \\
\hline
\end{tabular}


A final issue concerning the mixed-model scales labeled emotional intelligence is that unmoored from any constraints of the EI terminology, they sample across the domain of psychological traits in a haphazard fashion. As a consequence, at least some among the different self-judgment mixed-model EI scales in the area correlate at lower levels with one another than they do with the Big Five (Brackett \& Mayer, 2003).

Of course, tests such as the MSCEIT must meet additional psychometric standards as well: reliability, structural, convergent, and discriminant validity, among them. The split-half reliability of the overall EI score on the MSCEIT is $r=.91$, with reliabilities for the four branches between the high .70s to low .90s, and test-retest reliability in the high .80's (Mayer et al., 2003). Confirmatory factor analyses indicate that both a 1-factor model, indicating the presence of an overall EI, and four-factor models fit the data adequately, with other models possible (notably, a three factor model that combines Branches 1 and 2 is also plausible; Gignac, 2005; Mayer, Panter, Salovey, \& Sitaraneos, 2005; Mayer et al., 2003; Palmer, Gignac, Manocha, \& Stough, 2005).

One fly in the MSCEIT ointment concerns its convergent validity with other ability measures of specific EI skills. The convergence among ability measures of emotional perception such as the JACBART (Matsumoto et al., 2000), the DANVA (Nowicki \& Duke, 1994) and the MSCEIT is low, with most published values falling between $r=.00$ to .30 (Mayer, Roberts, \& Barsade, 2008). On the plus side, the subscales of the MSCEIT converge with one another (with $r$ 's $=.16$ to .58 ), despite using different response formats across branches (Mayer et al., 2003). MSCEIT scores also correlate with the ability to forecast one's future emotions (Dunn, Brackett, Ashton-James, Schneiderman, \& Salovey, 2007) and with the accurate perception of emotion in music (Resnicow, Salovey, \& Repp, 2004). Nonetheless, this issue is unsettling and requires further understanding (Mayer et al., 2008).

Compared to convergent validity evidence, discriminant validity evidence is promising. The very modest correlations between MSCEIT scores and traits of the Big Five (and other personality measures), as well as traditional intelligences, strongly indicate that the ability to reason about emotions (i.e., emotional intelligence) is a new construct. We earlier reported some MSCEIT-Big Five correlations; the MSCEIT total score correlates at similarly low levels, in the $r=.20$ to .35 range, with verbal intelligence and empathy (Mayer et al., 2004).

A number of observers and commentators on the field have expressed reservations about whether such tests are adequate measures of emotional intelligence, and whether they predict important outcomes (e.g., Brody, 2004; Oatley, 2004; Zeidner, Matthews, \& Roberts, 2001). The recent Annual Review of Psychology examination of EI and its measurement covers such concerns in greater detail, and summarizes many of the central, continuing issues (Mayer et al., 2008). To date, however, we believe that ability scales provide the best benchmark for this new construct.

\section{THE SIGNIFICANCE OF EMOTIONAL INTELLIGENCE}

\section{General Considerations of the Validity of an EI Measure}

We recognize that the MSCEIT has important limitations, and yet we consider it among the better and most widely used of the valid measures available. As such, we will focus on it in this section. The measurement issues surrounding EI are elements of broader questions: Is a measure such as the MSCEIT a valid assessment of emotional intelligence? And, can a test such as the MSCEIT account for new variance in important outcomes? In the mid- $20^{\text {th }}$ century, 
psychologists believed that such questions about validity could be answered based on findings from key correlational and experimental studies of the test itself (e.g., Barley, 1962).

A more contemporary view, by contrast, considers the validity of a test a consequence of ongoing critical evaluation not only of the test itself, but also of the theoretical framework supporting it, and its embeddedness in broader conceptualizations. For example, a test's measure of a concept depends on how the test author(s) define the concept, and that definition will be reliant, in turn, on other hypotheses and definitions, sometimes referred to as auxiliary theories. As summarized by Smith:

...In part for this reason, no theory is ever fully proved or disproved. At any given time, evidence tends to favor some theories or research programs, over others (Smith, 2005, pp. 397-398).

Thus far, the measurement evidence tends to favor the ability-based EI approach described here when compared to other research alternatives (such as dismissing EI or using mixed models). Valid approaches to EI can be divided into two central areas: specific-ability approaches, such as the study of accurate emotional perception, and integrative models of EI, one example of which is the four-branch model and the MSCEIT (see Mayer et al., 2008, for other measures). Drawing on revised criteria for test validity (Joint Committee on Standards, 1999), and surveying a diverse group of measures, a recent review of EI research concluded that generally, specific and integrative models, and the tests stemming from them, exhibited good evidence for the valid measure of EI (Mayer et al., 2008). Mixed models also were reviewed but were not considered to yield adequate measures of EI.

Here, we elaborate more specifically on the validity - both general and incremental - of the MSCEIT measure and the four-branch approach, particularly as it relates to clinical and applied phenomena. Hunsley and Meyer (2003; cf. McFall, 2005) note that "The concept of incremental validity is essentially a simple and straightforward one: does a measure add to the prediction of a criterion above what can be predicted by other sources of data?" (p. 446). Secondarily, new measures can increment conceptual clarity and understanding within a field. Journalistic accounts of EI raised such unrealistic ideas as that " $90 \%$ of the difference" between star performers and other workers is attributable to "emotional intelligence factors," and that $85 \%$ of success could be attributed to EI (Goleman, 1998a, p. 94; Watkin, 2000, p. 89) claims we have repeatedly pointed out are misleading and unsupported by research (e.g., Mayer, 1999; Mayer \& Cobb, 2000; Mayer \& Salovey, 1997; Mayer et al., 2000). Emotional intelligence is just one variable among many other mental abilities, cognitive styles, and socioemotional traits, and EI should predict important outcomes at levels usually found for other such psychological variables. Predictions from psychological measures to outcome variables are considered satisfactory for complex behavior in the $r=.10$ to .20 range, good in the $r=.20$ to .30 range, and still better when higher than $r=.30$ (Meyer et al., 2001, p. 134). With this in mind, some of the key findings regarding EI and social relationships are shown in Table 2. We selected a small number of results we consider representative of positive findings in this area.

\section{EI and Understanding Feelings}

Higher EI does appear to promote better attention to physical and mental processes relevant to clinical outcomes. For example, people higher in some emotional intelligence skills are more accurate in detecting variations in their own heartbeat - an emotion-related physiological response (Schneider, Lyons, \& Williams, 2005). Higher EI individuals also are better able to recognize and reason about the emotional consequences of events. For example, higher EI individuals are more accurate in affective forecasting - that is, in predicting how they will feel at some point in the 
future in response to an event, such as the outcome of a U.S. presidential election (Dunn et al., 2007).

Table 2: Selected Correlations From Several Studies Indicating that High EI is Associated with Better Social Relations; Low EI with Deviant Behavior ${ }^{\mathrm{a}, \mathrm{b}}$

\begin{tabular}{|c|c|c|}
\hline Study and Criterion Measure & $\begin{array}{l}\text { Correlation } \\
\text { with EI }\end{array}$ & $\begin{array}{l}\text { Incremental } \\
\text { Relation/ } \\
\text { Partial } \\
\text { Correlation } \\
\text { With EI }\end{array}$ \\
\hline \multicolumn{3}{|l|}{ David (2005) } \\
\hline SCL-90-R Global Severity Index & $-31 * *$ & $\Delta \mathrm{R}^{2}=3 \%$ \\
\hline SCL-90-R Positive Symptom Total & $-38 * *$ & $\Delta \mathrm{R}^{2}=6 \%$ \\
\hline SCL-90-R Positive Symptom Distress & $-22 * *$ & $\Delta \mathrm{R}^{2}=1 \%$ \\
\hline \multicolumn{3}{|l|}{ Lopes et al. (2005) } \\
\hline Peer nominations of interpersonal sensitivity & $.29 *$ & -- \\
\hline $\begin{array}{l}\text { Peer nominations of interpersonal competence, dominance, } \\
\text { and assertiveness }\end{array}$ & .05 & -- \\
\hline Reciprocal friendship nominations & $.23 *$ & -- \\
\hline \multicolumn{3}{|l|}{ Rosete (2007) } \\
\hline Manager's rating of achieving business outcomes & .26 & $B=.24, p<.01$ \\
\hline Manager's effective interpersonal behaviors & .52 & $\beta=.49, \mathrm{p}<.01$ \\
\hline \multicolumn{3}{|l|}{ Brackett \& Mayer ( 2003) } \\
\hline $\begin{array}{l}\text { Illegal Drug Use (Amount of marijuana owned? Times } \\
\text { used illegal drugs in last month?) }\end{array}$ & -.05 & -.07 \\
\hline $\begin{array}{l}\text { Social Deviance (Number of physical fights in the last } \\
\text { year? Number of times vandalized something?) }\end{array}$ & $-.27 * *$ & $-.20 * *$ \\
\hline \multicolumn{3}{|l|}{ Brackett, Mayer, \& Warner, (2004) } \\
\hline $\begin{array}{l}\text { Illegal Drug Use (Times smoked marijuana in the last } \\
\text { month? Money spent on drugs in last month?) }\end{array}$ & -.32 & -- \\
\hline $\begin{array}{l}\text { Deviant Behavior (Men only) (Number of physical fights } \\
\text { in last year? Times vandalized something last year?) }\end{array}$ & -.45 & -- \\
\hline \multicolumn{3}{|l|}{ Trinidad \& Johnson (2002) } \\
\hline Overall Tobacco and Alcohol Use & $-.19 *$ & $-.20 *$ \\
\hline
\end{tabular}

a. The criterion scale is the MSCEIT for most studies. Trinidad \& Johnson employed the MEIS, which was a precursor ability scale to the MSCEIT (Mayer et al., 1999)

b. For more complete reporting, see (Mayer et al., 2004)

EI and Subjective Symptoms

Abilities such as affective forecasting are important, for example, because psychotherapy patients from a wide diversity of backgrounds seek help with the hopes of gaining insight into their feelings and motives (Evans, Acosta, \& Yamamoto, 1986; Noble, Douglas, \& Newman, 1999). If EI increases the attention to and accuracy of knowing one's feelings under various conditions, this could, in turn, minimize one's psychiatric symptoms. David (2005) examined EI and psychiatric distress on the Symptom Checklist (SCL-90-R). The higher a person's EI, the lower their reports of symptoms on the Positive Symptom Total, $r=-.38$, including, for example, 
fewer headaches and less trouble concentrating. The Symptom Distress Index, which measures symptom intensity, also declined as EI rose, $r=-.22$. After controlling for the Big Five personality dimensions, EI still accounted for between 1 to $6 \%$ of the variance in SCL scales supporting the incremental validity of EI (see Table 2). Other reports have indicated that, for example, those diagnosed with dysthymia have lower EI scores when compared to other psychiatric groups (Lizeretti, Oberst, Chamarro, \& Farriols, 2006).

\section{EI and Understanding Social Relationships}

Many psychotherapy clients hope to improve what have become problematic social behaviors and relationships (Evans et al., 1986; Noble et al., 1999). Research on EI indicates that people with high emotional intelligence tend to be more socially competent, have betterquality friendships, and are viewed as more interpersonally sensitive than those lower in EI (Brackett et al., 2006; Brackett, Warner, \& Bosco, 2005; Lopes et al., 2004; Lopes, Salovey, Côté, \& Beers, 2005; Lopes, Salovey, \& Straus, 2003). Many associations between EI and these kinds of variables remain significant even after controlling for the influence of traditional personality variables and general intelligence on the measured outcome.

In one study of friendships, the relationship between EI and a person's engagement in destructive responses to life events experienced by one's friends often were significant, even after controlling for the Big Five, psychological well-being, empathy, life satisfaction and Verbal SAT scores, but for men only (Brackett et al., 2006), with MSCEIT correlations ranging from $r=$ -.02 to -.33 .

Although the findings described above were based on self-evaluated outcome criteria, similar findings come from observer-reports of the same individuals. For example, judges' positive ratings of a videotaped "getting acquainted" social interaction were predicted by the MSCEIT, although again, only for men and not for women. Ratings of the ability to work well with others as well as overall judged social competence correlated $r=.53$ and .51 , respectively, with EI. The authors noted that significant correlations remained after partialing out the Big Five (Brackett et al., 2006).

Just as higher EI predicts better social outcomes, lower EI predicts interpersonal conflict and maladjustment. Teenagers lower in EI were rated as more aggressive than others and tended to engage in more conflictual behavior than their higher-EI peers (Mayer, Perkins, Caruso, \& Salovey, 2001; Rubin, 1999). Lower EI also predicted greater drug and alcohol abuse. For example, levels of drug and alcohol use are related to lower EI among males (Brackett, Mayer, \& Warner, 2004). Inner-city adolescents' smoking is also related to their EI (Trinidad \& Johnson, 2002).

\section{Understanding Work Relationships}

High EI correlates with better relationships in business settings as well. Managers higher in EI are better able to cultivate productive working relationships with others and to demonstrate greater personal integrity according to multi-rater feedback (Rosete \& Ciarrochi, 2005). EI also predicts the extent to which managers engage in behaviors that are supportive of the goals of the organization according to the ratings of their supervisors (Côté \& Miners, 2006). In one study, 38 manufacturing supervisors' managerial performance were evaluated by their 1258 employees. Total EI correlated $r=.39$ with these managerial performance ratings, with the strongest relations for the ability to perceive emotions and to use emotions (Kerr, Garvin, \& Heaton, 2006).

Rosete (2007) studied 122 public service managers' business and leadership performance and found that the MSCEIT related $r=.26$ to a supervisor's appraisal of a manager's effective 
business performance ("focuses strategically," "ensures closure and delivers on intended results") and $r=.52$ with an appraisal of a manager's effective interpersonal behaviors ("guides, mentors and develops people," "someone who communicates clearly"). A hierarchical regression analysis predicting effective business performance indicated that EI was a significant predictor, even after entering both an estimate of cognitive ability (16 PF scale B) and the Big Five. A similar analysis for the interpersonal behavior rating found that ability EI was also a significant predictor after controlling for cognitive ability and personality (see Table 2).

A somewhat more complex relationship between EI and other variables was found by Coté and Miners (2006). In their study, employees with low cognitive intelligence (scoring one standard deviation or more below the sample mean on the Culture Fair Intelligence Test) exhibited better performance and citizenship behavior if they scored higher on the MSCEIT but not otherwise, whereas those with high cognitive intelligence (one SD or more above the mean) showed no advantage of EI. In a small-sample study of employees in the finance division of an insurance company, higher MSCEIT scores were associated with positive ratings of work behavior by peers and supervisors as well as with recommendations for greater year-end salary increases (Lopes et al., 2006).

Considerations of Incremental Validity

Empirical evidence suggests that EI often contributes to incremental predictions of social effectiveness, over-and-above frequently employed measures of personality and intelligence, as exhibited in Table 2. The EI concept further increments our clarity in understanding why certain people - those who score higher on EI scales - are more successful in their relationships at home and at work. These higher EI individuals are better able to recognize and reason about their emotions, as well as about the emotional consequences of their decisions, and the emotions of others. Together, the empirical and conceptual increments indicate that EI is a useful variable for study.

\section{DISCUSSION AND RECOMMENDATIONS}

Emotional Intelligence as a

Valid and Significant New Concept

In this article, we have argued that there exists a valid and conceptually important new variable for investigators and practitioners. Emotional intelligence can be defined as an intelligence that explains important variance in an individual's problem solving and social relationships. Yet, the acceptance of the construct is threatened, perhaps, less by its critics than by those who are so enthusiastic about it as to apply the term indiscriminately to a variety of traditional personality variables (as pointed out by Daus \& Ashkanasy, 2003; Murphy \& Sideman, 2006).

Why Do Some Investigators and Practitioners Use the Term Emotional Intelligence Overly Broadly? Expansion of the Emotional and Cognitive Areas of Thinking

Why are traits such as the need for achievement, self-control, and social effectiveness (let alone character and leveraging diversity) sometimes referred to as emotional intelligence? Perhaps one contributing cause is a lack of perspective on personality as a whole. Psychology needs good overviews of the central areas of mental function - models that define personality's major areas. Yet few such overviews reached any level of currency or consensus in the psychology of the 1980s and 1990s. Hilgard (1980) indicated that psychology is thrown out-ofbalance by the absence of such models. Indeed, the cognitive revolution of the 1970s and 1980s 
(Miller, 2003), followed by the intense interest in affective (emotional) sciences in the 1980s and 1990s (e.g., Barsade, Brief, \& Spataro, 2003), contributed to a sense that cognitive and emotional systems were dominant aspects of the whole of personality. Many psychologists and other investigators began to refer to cognition, affect, and behavior, as though it provided complete coverage of the study of mental life (e.g., Thompson \& Fine, 1999). In that impoverished context, the term emotional intelligence could be mistaken as a label for much of mental processing. In fact, however, the three-legged stool of cognition, affect, and behavior underemphasizes such areas of personality as representations of the self, motivation, and self-control processes; more comprehensive models have since been proposed (Mayer, 2003, 2005; McAdams \& Pals, 2006).

\section{Reaction to the Big Five}

Also during the 1980s and 1990s, the most pervasive empirical work in personality psychology involved the study of the Big Five traits (Goldberg, 1993; Goldberg \& Rosolack, 1994; John \& Srivastava, 1999) - so much so, that many people identified personality as merely, or essentially, the Big Five (Block, 1995). Yet that Big Five model dispossessed many traditionally important personality variables (Block, 1995; Mayer, 2005). There was a reaction against the Big Five model which had, during those years, so represented the field.

The advent of emotional intelligence encouraged some to revisit a number of social and emotional traits and conceive of them as forming new models of social effectiveness and well being. Furnham and Petrides included self-judged adaptability, assertiveness, social competence, and stress management, among others, in their model, which were included under those authors' label trait emotional intelligence (Petrides \& Furnham, 2001, pp. 40, 47). Acknowledging the considerable overlap between their dimensions and those of the Big Five traits, they stated:

...even if there were complete overlap between trait EI and the main personality dimensions... We believe that the theoretical and explanatory power of any psychological construct, including trait EI, is much more important than its incremental validity... (Petrides \& Furnham, 2001, p. 54).

Their research was recently used as part of the basis for the launch of yet another self-judgment scale under the name EI (Tett et al., 2005).

Although we agree that theoretical clarity is, at times, more important than incremental validity, we also believe in staying within scientific bounds in the use of such terms as emotion and intelligence - unless, of course, such terms require revision. Those investigators who wander outside the conceptual network, however, offer no rationale for revising such terms.

\section{The Seduction of the Emotional}

There is a broader cultural perspective, as well, that may promote such yearnings for a broader emotional intelligence. Throughout history, philosophers and pundits alike have argued about whether to follow one's "head" or "heart." Through much of this time, the "heads" have had the upper hand, so to speak. The Stoic tradition that thought trumps emotions is wellembedded in Western philosophy. Still, at times, those with emotional urges have leapt forward to argue that the heart should be all-important. It appears that some of our writings have inspired a bit of an outbreak of that type.

And yet, this would be a mistake as it represents a false dichotomy (cf. Damasio, 1994). Relying on emotional characteristics, or on motives, or on any single part of personality would leave the individual unbalanced, from our perspective. A truly healthy individual has neither thought alone, nor emotion alone, but a functional integration among their major psychological 
processes. In this view, mental energy - a combination of motives and emotions - works with adaptive thinking, and leads to effective behaviors, all the while being monitored, guided, and controlled, where necessary by self-consciousness (Mayer, 2007). Being warm is not enough (although it may be pleasant), ditto exhibiting assertiveness. Rather, it all must come together for personality to work.

\section{Our Viewpoint}

We agree with a number of observers of the area that emotional intelligence is used in too all-inclusive a fashion and in too many different ways (Landy, 2005; Locke, 2005; Matthews et al., 2004; Murphy, 2006). Referring to the broadened definitions in particular, Locke remarked, "What does EI...not include?" (Locke, 2005, p. 428) We believe that there is a valid EI concept. However, we certainly agree that there is widespread misuse of the term to apply to concepts that simply are not concerned with emotion or intelligence or their intersection. The misuses of the term are, to us, invalid in that they attempt to overthrow or subvert the standard scientific language in psychology, with no apparent rationale for so doing. Other investigators similarly have pointed out that it is important to distinguish between valid and invalid uses of the concept (Daus \& Ashkanasy, 2005; Gohm, 2004); to date, however, this message has not been heeded as we believe it should be.

Recommendations

...The tradition of exaggerated tenderness in psychiatry and psychology reflects our "therapeutic attitude" and contrasts with that of scholars in fields like philosophy or law, where a dumb argument is called a dumb argument, and he who makes a dumb argument can expect to be slapped down by his peers...(Meehl, 1973, p. 228).

Those investigators interested in EI increasingly are asking to clarify what is and is not legitimate work in the field. Murphy and Sideman (2006, p. 296) put it as to "succeed in separating the valid work from the hype." One central concern of our own (and of others), here and elsewhere, has been to distinguish better from poorer approaches to EI.

From our perspective, renaming the Big Five and other classic personality traits as "emotional intelligence" reflects a lack of understanding of personality theory and undermines good scientific practice. It obscures the meaning of emotional intelligence, and emotional intelligence is an important enough new construct as to make that unfortunate and problematic. It is only when the term is reverted to its legitimate meaning within the conceptual, scientific network, that it can be taken seriously (Cronbach \& Meehl, 1955; Joint Committee on Standards, 1999). There are a good number of researchers who understand this, and who have used the term consistently in a meaningful fashion. As for the others, one of the reasons for writing this article is to convince them of the common sense of using the current personality terminology. On a very practical level, it is often impossible to evaluate a journal article purporting to study emotional intelligence based upon keywords or the abstract: The study may examine well-being, assertiveness, self-perceptions of emotional abilities, or actual abilities.

We have provided an overview of emotional intelligence in particular with an eye to help distinguish emotional intelligence from other more traditional personality variables. We have attempted to make it clearer than before where emotional intelligence begins and ends, and where other personality approaches pick up. Much of the mixed-model research on EI (sometimes called EQ), can be described by Lakatos (1968, as cited by Smith, 2005) as a "degenerating research program" which consists of a series of defensive shifts in terminology and hypotheses "unlikely to yield new knowledge or understanding" (Smith, 2005, p. 401). 
We realize that the recommendations below may be obvious to many, even to those who have not read our article. To be as clear as we can be, however, we propose a set of simple recommendations that we believe will help to safeguard the field and foster its progress.

Recommendation 1: In our opinion, the journalistic popularizations of EI frequently employ inadequate and overly broad definitions of EI, implausible claims, and misunderstandings of the concepts and research more generally. We urge researchers and practitioners alike to refer to the scientific literature on emotions, intelligence, and emotional intelligence to guide their thinking. Simply put, researchers need to cite the research literature rather than journalistic renderings of scientific concepts, which serve a different purpose.

Recommendation 2: Referring to the diverse approaches to EI, one research group observed: "It is precisely because of this heterogeneity that we need clear conceptualization and definition" (Zeidner et al., 2004, p. 247). To restore clarity to the study of EI, we recommend that the term emotional intelligence be limited to abilities at the intersection between emotions and intelligence - specifically limited to the set of abilities involved in reasoning about emotions, and of using emotions to enhance reasoning.

Recommendation 3: We recommend that those interested in EI refocus on research relevant to the ability conception of emotional intelligence. This includes studies using emotional knowledge measures, emotional facial recognition ability, levels of emotional awareness, emerging research on emotional self-regulation, and related areas (e.g., Elfenbein \& Ambady, 2002b; Izard et al., 2001; Lane et al., 1990; Mayer et al., 2003; Nowicki \& Mitchell, 1998).

Recommendation 4: We recommend that groups of widely studied personality traits, including motives such as the need for achievement, self-related concepts such as self-control, emotional traits such as happiness, and social styles such as assertiveness should be called what they are, rather than being mixed together in haphazard-seeming assortments and named emotional intelligence.

Recommendation 5: Much remains unknown about emotional intelligence (Matthews, Zeidner, \& Roberts, 2007). Our final recommendation is that, following the clearer terminology and conceptions above, good theorizing and research in emotional intelligence continue until more is known about the concept, and human mental abilities more generally. Enough has been learned to indicate that this is a promising area, but also that significant gaps in knowledge remain. For example, there needs to be greater attention to issues of culture and gender and their impact on theories of emotional intelligence and the measurement of emotional intelligence. Further progress in the measurement of emotional intelligence generally is also required. The MSCEIT, we believe, is a useful, integrative approach to measuring emotional intelligence, although we acknowledge that the test has its limits, for example, in the assessment of emotional perception (e.g., O'Sullivan \& Ekman, 2004; Roberts et al., 2006). Applications of EI must be conducted with much greater attention to the research literature, be grounded in good theory, and reject outlandish claims.

We realize that there are many stakeholders in this area, a number of whom would naturally hope to continue using the term emotional intelligence as they have been. We hope that highlighting, on the one hand, the valid criticism of the overly-broad uses of the EI term, and by recommending alternatives, we can apply some persuasion gradually to discourage such usage, and make others aware of its problematic nature. That said, we continue to believe that emotional intelligence is an important, newly described construct. It organizes a number of specific mental abilities having to do with identifying, understanding, managing, and using 
emotions, it is distinct from other constructs, it unifies a set of heretofore diverse set of psychological processes for examination, and it makes practical, though modest, predictions about key interpersonal behaviors.

In this article, we hope to have separated this emotional intelligence from other constructs that may be important in their own rights but are ill-labeled as emotional intelligence. By clarifying our model and discussing some of the confusion in the area, we hope to encourage researchers and practitioners to distinguish emotional intelligence from other domains of study. Such distinctions will help pave the way for a healthier, more convincing, and better understood emotional intelligence, one that best can serve the discipline of psychology and other fields.

\section{REFERENCES}

Archer, D., Costanzo, M., \& Akert, R. (2001). The Interpersonal Perception Task (IPT): Alternative approaches to problems of theory and design. In J. A. Hall \& F. J. Bernieri (Eds.), Interpersonal sensitivity: Theory and measurement (pp. 161-182). Mahwah, NJ: Lawrence Erlbaum Associates.

Averill, J. R. (1992). The structural bases of emotional behavior: A metatheoretical analysis. Review of Personality and Social Psychology, 13, 1-24.

Bar-On, R. (1997). BarOn Emotional Quotient Inventory: Technical manual. Toronto, Canada: MultiHealth Systems.

Bar-On, R. (2004). The Bar-On Emotional Quotient Inventory (EQ-i): Rationale, description and summary of psychometric properties. In G. Geher (Ed.), Measuring emotional intelligence: Common ground and controversy (pp. 115-145). New York: Nova Science Publishers.

Barley, W. W. (1962). The retreat to commitment. New York: A. A. Knopf.

Barrett, L. F., \& Russell, J. A. (1999). The structure of current affect: Controversies and emerging consensus. Current Directions in Psychological Science, 8, 10-14.

Barsade, S. G., Brief, A. P., \& Spataro, S. E. (2003). The affective revolution in organizational behavior: The emergence of a paradigm. In J. Greenberg (Ed.), Organizational behavior: The state of the science (2nd ed., pp. 3-52). Mahwah, NJ: Lawrence Erlbaum Associates.

Block, J. (1995). A contrarian view of the five-factor approach to personality description. Psychological Bulletin, 117, 187-215.

Boyatzis, R. E., \& Sala, F. (2004). The Emotional Competence Inventory (ECI). In G. Geher (Ed.), Measuring emotional intelligence: Common ground and controversy (pp. 147-180). New York: Nova Science Publishers.

Brackett, M. A., Kremenitzer, J. P., Maurer, M., Carpenter, M. D., Rivers, S. E., \& Katulak, N. A. (2007). Emotional literacy in the classroom: Upper elementary. Port Chester, NY: Dude Publishing.

Brackett, M. A., \& Mayer, J. D. (2003). Convergent, discriminant, and incremental validity of competing measures of emotional intelligence. Personality and Social Psychology Bulletin, 29, 1147-1158.

Brackett, M. A., Mayer, J. D., \& Warner, R. M. (2004). Emotional intelligence and the prediction of behavior. Personality and Individual Differences, 36, 1387-1402.

Brackett, M. A., Rivers, S. E., Shiffman, S., Lerner, N., \& Salovey, P. (2006). Relating emotional abilities to social functioning: A comparison of self-report and performance measures of emotional intelligence. Journal of Personality and Social Psychology, 91, 780-795.

Brackett, M. A., Warner, R. M., \& Bosco, J. (2005). Emotional intelligence and relationship quality among couples. Personal Relationships, 12, 197-212.

Brody, N. (2004). What cognitive intelligence is and what emotional intelligence is not. Psychological Inquiry, 15, 234-238.

Bureau of Personnel Administration. (1930). Partially standardized tests of social intelligence. Public Personnel Studies, 8, 73-79.

Carlson, J. G., \& Hatfield, E. (1992). Psychology of emotion. San Diego, CA: Harcourt Brace Jovanovich. 
Carroll, J. B. (1993). Human cognitive abilities: A survey of factor analytic studies. New York: Cambridge University Press.

Ciarrochi, J. V., Chan, A. Y., \& Caputi, P. (2000). A critical evaluation of the emotional intelligence concept. Personality and Individual Differences, 28, 539-561.

Clore, G. L., Ortony, A., \& Foss, M. A. (1987). The psychological foundations of the affective lexicon. Journal of Personality and Social Psychology, 53, 751-766.

Costa, P. T., \& McCrae, R. R. (1992). Revised NEO Personality Inventory (NEO-PI-R) and NEO FiveFactor Inventory (NEO-FFI) professional manual. Odessa, FL: Psychological Assessment Resources.

Côté, S., \& Miners, C. T. H. (2006). Emotional intelligence, cognitive intelligence and job performance. Administrative Science Quarterly, 51, 1-28.

Cronbach, L. J. (1960). Essentials of psychological testing (2nd ed.). New York: Harper \& Row.

Cronbach, L. J., \& Meehl, P. E. (1955). Construct validity in psychological tests. Psychological Bulletin, 52, 281-302.

Damasio, A. R. (1994). Descartes' error. New York: G. P. Putnam's Sons.

Darwin, C. (1872/1998). The expression of the emotions in man and animals; with an introduction, afterword, and commentaries by Paul Ekman (3rd ed.). New York: Oxford University Press. (Original work published 1872).

Daus, C. S., \& Ashkanasy, N. M. (2003). Will the real emotional intelligence please stand up? On deconstructing the emotional intelligence "debate". The Industrial-Organizational Psychologist, $41,69-72$.

Daus, C. S., \& Ashkanasy, N. M. (2005). The case for the ability-based model of emotional intelligence in organizational behavior. Journal of Organizational Behavior, 26, 453-466.

David, S. A. (2005). Emotional intelligence: Conceptual and methodological issues, and its role in coping and well-being. Unpublished doctoral dissertation, University of Melbourne, Melbourne.

Dawda, D., \& Hart, S. D. (2000). Assessing emotional intelligence: Reliability and validity of the Bar-On Emotional Quotient Inventory (EQ-i) in university students. Personality \& Individual Differences, 28, 797-812.

Dunn, E. W., Brackett, M. A., Ashton-James, C., Schneiderman, E., \& Salovey, P. (2007). On emotionally intelligent time travel: Individual differences in affective forecasting ability. Personality and Social Psychology Bulletin, 33, 85-93.

Dyer, M. G. (1983). The role of affect in narratives. Cognitive Science, 7, 211-242.

Ekman, P. (1973). Darwin and facial expression: A century of research in review. New York: Academic Press.

Elfenbein, H. A., \& Ambady, N. (2002a). On the universality and cultural specificity of emotion recognition: A meta-analysis. Psychological Bulletin, 128, 203-235.

Elfenbein, H. A., \& Ambady, N. (2002b). Predicting workplace outcomes from the ability to eavesdrop on feelings. Journal of Applied Psychology, 87, 963-971.

Evans, L. A., Acosta, F. X., \& Yamamoto, J. (1986). Patient requests: Correlates and therapeutic implications for Hispanic, Black, and Caucasian patients. Journal of Clinical Psychology, 42, 213-221.

Frijda, N. H. (1988). The laws of emotion. American Psychologist, 43, 349-358.

Gardner, H. (1983). Frames of mind: The theory of multiple intelligences. New York: Basic Books.

Geher, G., Warner, R. M., \& Brown, A. S. (2001). Predictive validity of the emotional accuracy research scale. Intelligence, 29, 373-388.

Gibbs, N. (1995, October 2). The EQ factor. Time, 146, 60-68.

Gignac, G. E. (2005). Evaluating the MSCEIT V2.0 via CFA: Comment on Mayer et al. (2003). Emotion, $5,233-235$.

Gohm, C. L. (2004). Moving forward with emotional intelligence. Psychological Inquiry, 15, 222-227.

Goldberg, L. R. (1993). The structure of phenotypic personality traits. American Psychologist, 48, $26-34$. 
Goldberg, L. R., \& Rosolack, T. K. (1994). The Big Five factor structure as an integrative framework: An empirical comparison with Eysenck's P-E-N model. In C. F. Halverson, G. A. Kohnstamm \& R. P. Martin (Eds.), The developing structure of temperament and personality from infancy to adulthood (pp. 7-35). Hillsdale, NJ: Lawrence Erlbaum Associates.

Goleman, D. (1995). Emotional intelligence. New York: Bantam.

Goleman, D. (1998a). What makes a leader? Harvard Business Review, 76, 93-102.

Goleman, D. (1998b). Working with emotional intelligence. New York: Bantam.

Goleman, D. (2005). Emotional intelligence. New York: Bantam.

Goodrum, S. (2005). The interaction between thoughts and emotions following the news of a loved one's murder. Omega: Journal of Death and Dying, 51, 143-160.

Gosling, S. D., Rentfrow, P. J., \& Swann, W. B. J. (2003). A very brief measure of the Big-Five personality domains. Journal of Research in Personality, 37, 504-528.

Guilford, J. P. (1959). Personality. New York: McGraw-Hill.

Hilgard, E. R. (1980). The trilogy of mind: Cognition, affection, and conation. Journal of the History of the Behavioral Sciences, 16, 107-117.

Hunsley, J., \& Meyer, G. J. (2003). The incremental validity of psychological testing and assessment: Conceptual, methodological, and statistical issues. Psychological Assessment, 15, 446-455.

Izard, C., Fine, S., Schultz, D., Mostow, A. J., Ackerman, B., \& Youngstrom, E. (2001). Emotion knowledge as a predictor of social behavior and academic competence in children at risk. Psychological Science, 12, 18-23.

James, W. (1892/1920). Psychology: Briefer course. New York: Henry Holt.

John, O. P., \& Srivastava, S. (1999). The big five trait taxonomy: History, measurement, and theoretical perspectives. In O. P. John \& L. A. Pervin (Eds.), Handbook of personality: Theory and research (2nd ed.). New York/London: The Guilford Press.

Joint Committee on Standards. (1999). Standards for educational and psychological testing. Washington, DC: American Educational Research Association.

Kaufman, A. S. (2000). Tests of intelligence. In R. J. Sternberg (Ed.), Handbook of intelligence (pp. 445476). New York, NY: Cambridge University Press.

Kerr, R., Garvin, J., \& Heaton, N. (2006). Emotional intelligence and leadership effectiveness. Leadership \& Organization Development Journal, 27, 265-279.

Landy, F. J. (2005). Some historical and scientific issues related to research on emotional intelligence. Journal of Organizational Behavior, 26, 411-424.

Lane, R. D., Quinlan, D. M., Schwartz, G. E., Walker, P. A., \& Zeitlin, S. B. (1990). The Levels of Emotional Awareness Scale: A cognitive-developmental measure of emotion. Journal of Personality Assessment, 55, 124-134.

Lazarus, R. S. (1991). Emotion and adaptation. New York, NY: Oxford University Press.

LeDoux, J. E. (2000). Emotion circuits in the brain. Annual Review of Neuroscience, 23, 155-184.

Lewis, M., \& Haviland-Jones. (2000). Handbook of emotions (2nd ed.). New York: Guilford Press.

Lizeretti, N. P., Oberst, U., Chamarro, A., \& Farriols, N. (2006). Evaluación de la inteligencia emocional en pacientes con psicopatología: Resultados preliminares usando el TMMS-24 y el MSCEIT. Ansiedad y Estrés, 12, 355-364.

Locke, E. A. (2005). Why emotional intelligence is an invalid concept. Journal of Organizational Behavior, 26, 425-431.

Lopes, P. N., Brackett, M. A., Nezlek, J. B., Schütz, A., Sellin, I., \& Salovey, P. (2004). Emotional intelligence and social interaction. Personality and Social Psychology Bulletin, 30, 1018-1034.

Lopes, P. N., Côté, S., Grewal, D., Salovey, P., Kadis, J., \& Gall, M. (2006). Evidence that emotional intelligence is related to job performance, interpersonal facilitation, affect and attitudes at work, and leadership potential. Psicothema, 18, 132-138.

Lopes, P. N., Salovey, P., Côté, S., \& Beers, M. (2005). Emotion regulation abilities and the quality of social interaction. Emotion, 5, 113-118. 
Lopes, P. N., Salovey, P., \& Straus, R. (2003). Emotional intelligence, personality, and the perceived quality of social relationships. Personality \& Individual Differences, 35, 641-658.

MacLean, P. D. (1973). A triune concept of the brain and behavior. Toronto: University of Toronto Press.

Matarazzo, J. D. (1972). Wechsler's measurement and appraisal of adult intelligence (5th ed.). New York: Oxford University Press.

Mathews, G., Zeidner, M., \& Roberts, R. D. (2002). Emotional intelligence: Science and myth. Cambridge: MIT Press.

Matsumoto, D., LeRoux, J., \& Wilson-Cohn, C. (2000). A new test to measure emotion recognition ability: Matsumoto and Ekman's Japanese and Caucasian Brief Affect Recognition Test (JACBART). Journal of Nonverbal Behavior, 24, 179-209.

Matthews, G., Roberts, R. D., \& Zeidner, M. (2004). Seven myths about emotional intelligence. Psychological Inquiry, 15, 179-196.

Matthews, G., Zeidner, M., \& Roberts, R. D. (2002). Emotional intelligence: Science and myth. Cambridge: MIT Press.

Matthews, G., Zeidner, M., \& Roberts, R. D. (2007). Emotional intelligence: Knowns and unknowns. Cambridge, MA: Oxford University Press.

Maurer, M., \& Brackett, M. (2004). Emotional literacy in the middle school. Port Chester, NY: Dude Publishing.

Mayer, J. D. (1999). Emotional Intelligence: Popular or scientific psychology? APA Monitor, 30, 50.

Mayer, J. D. (2003). Structural divisions of personality and the classification of traits. Review of General Psychology, 7, 381-401.

Mayer, J. D. (2005). A tale of two visions: Can a new view of personality help integrate psychology? American Psychologist, 60, 294-307.

Mayer, J. D. (2006). A new field guide to emotional intelligence. In J. Ciarrochi, J. P. Forgas \& J. D. Mayer (Eds.), Emotional intelligence in everyday life (2nd ed., pp. 3-26). New York: Psychology Press.

Mayer, J. D. (2007). Personality function and personality change. In J. Ciarrochi \& J. D. Mayer (Eds.), Applying emotional intelligence (pp. 125-143). New York: Psychology Press.

Mayer, J. D., Caruso, D. R., \& Salovey, P. (1999). Emotional intelligence meets traditional standards for an intelligence. Intelligence, 27, 267-298.

Mayer, J. D., \& Cobb, C. D. (2000). Educational policy on emotional intelligence: Does it make sense? Educational Psychology Review, 12, 163-183.

Mayer, J. D., DiPaolo, M. T., \& Salovey, P. (1990). Perceiving affective content in ambiguous visual stimuli: A component of emotional intelligence. Journal of Personality Assessment, 54, 772-781.

Mayer, J. D., Panter, A. T., Salovey, P., \& Sitaraneos, G. (2005). A discrepancy in analyses of the MSCEIT--resolving the mystery and understanding its implications: A reply to Gignac (2005). Emotion, 5, 236-237.

Mayer, J. D., Perkins, D., Caruso, D. R., \& Salovey, P. (2001). Emotional intelligence and giftedness. Roeper Review, 23, 131-137.

Mayer, J. D., Roberts, R. D., \& Barsade, S. G. (2008). Human abilities: Emotional intelligence. Annual Review of Psychology, 59, 507-536.

Mayer, J. D., \& Salovey, P. (1993). The intelligence of emotional intelligence. Intelligence, 17, 433-442.

Mayer, J. D., \& Salovey, P. (1997). What is emotional intelligence? In P. Salovey \& D. Sluyter (Eds.), Emotional development and emotional intelligence: Educational implications (pp. 3-31). New York: Basic Books.

Mayer, J. D., Salovey, P., \& Caruso, D. R. (2000). Models of emotional intelligence. In R. J. Sternberg (Ed.), Handbook of intelligence (pp. 396-420). Cambridge, England: Cambridge University Press.

Mayer, J. D., Salovey, P., \& Caruso, D. R. (2002). Mayer-Salovey-Caruso Emotional Intelligence Test (MSCEIT) user's manual. Toronto, Canada: MHS Publishers.

Mayer, J. D., Salovey, P., \& Caruso, D. R. (2004). Emotional intelligence: Theory, findings, and implications. Psychological Inquiry, 60, 197-215. 
Mayer, J. D., Salovey, P., Caruso, D. R., \& Sitarenios, G. (2001). Emotional intelligence as a standard intelligence. Emotion, 1, 232-242.

Mayer, J. D., Salovey, P., Caruso, D. R., \& Sitarenios, G. (2003). Measuring emotional intelligence with the MSCEIT V2.0. Emotion, 3, 97-105.

McAdams, D. P., \& Pals, J. L. (2006). A new big five: Fundamental principles for an integrative science of personality. American Psychologist, 61, 204-217.

McFall, R. M. (2005). Theory and utility -- Key themes in evidence-based assessment: Comment on the special section. Psychological Assessment, 17, 312-325.

Meehl, P. E. (1973). Why I do not attend case conferences. In P. E. Meehl (Ed.), Psychodiagnosis: Selected papers (pp. 225-302). New York: W. W. Norton.

Mesquita, B. (2001). Emotions in collectivist and individualist contexts. Journal of Personality and Social Psychology, 80, 68-74.

Meyer, G. J., Finn, S. E., Eyde, L. D., Kay, G. G., Moreland, L. K., Dies, R. R., et al. (2001). Psychological testing and psychological assessment: A review of evidence and issues. American Psychologist, 56, 128-165.

Miller, G. A. (2003). The cognitive revolution: A historical perspective. Trends in Cognitive Sciences, 7 , $141-144$.

Murensky, C. L. (2000). The relationships between emotional intelligence, personality, critical thinking ability and organizational leadership performance at upper levels of management. Dissertation Abstracts International: Section B: The Sciences \& Engineering, 61(2-B), 1121 (US: Univ Microfilms International ISSN/ISBN: 0419-4217).

Murphy, K. R. (Ed.). (2006). A critique of emotional intelligence: What are the problems and how can they be fixed? Mahwah, NJ: Lawrence Erlbaum Associates.

Murphy, K. R., \& Sideman, L. (2006). The fadification of emotional intelligence. In K. R. Murphy (Ed.), A critique of emotional intelligence: What are the problems and how can they be fixed (pp. 283299). Mahwah, NJ: Lawrence Erlbaum Associates.

Neisser, U., Boodoo, G., Bouchard, T. J., Boykin, A. W., Brody, N., Ceci, S. J., et al. (1996). Intelligence: Knowns and unknowns. American Psychologist, 51, 77-101.

Newsome, S., Day, A. L., \& Catano, V. M. (2000). Assessing the predictive validity of emotional intelligence. Personality and Individual Differences, 29, 1005-1016.

Noble, L. M., Douglas, B. C., \& Newman, S. P. (1999). What do patients want and do we want to know? A review of patients' requests of psychiatric services. Acta Psychiatrica Scandinavica, 100, 321327.

Nowicki, S. J., \& Duke, M. P. (1994). Individual differences in the nonverbal communication of affect: The diagnostic analysis of nonverbal accuracy scale. Journal of Nonverbal Behavior, 19, 9-35.

Nowicki, S. J., \& Mitchell, J. (1998). Accuracy in identifying affect in child and adult faces and voices and social competence in preschool children. Genetic, Social, \& General Psychology Monographs, 124, 39-59.

O'Sullivan, M., \& Ekman, P. (2004). Facial expression recognition and emotional intelligence. In G. Geher (Ed.), Measuring emotional intelligence: Common ground and controversy (pp. 91-111). Hauppauge, NY: Nova Science.

Oatley, K. (2004). Emotional intelligence and the intelligence of emotions. Psychological Inquiry, 15, 216-221.

Oatley, K., \& Jenkins, J. M. (1996). Understanding emotions. Oxford: Blackwell.

Ortony, A., Clore, G. L., \& Collins, A. M. (1988). The cognitive structure of emotions. Cambridge, UK: Cambridge University Press.

Palmer, B. R., Gignac, G., Manocha, R., \& Stough, C. (2005). A psychometric evaluation of the MayerSalovey-Caruso Emotional Intelligence Test Version 2.0. Intelligence, 33, 285-305.

Petrides, K. V., \& Furnham, A. (2001). Trait emotional intelligence: Psychometric investigation with reference to established trait taxonomies. European Journal of Personality, 15, 425-448. 
Petrides, K. V., \& Furnham, A. (2003). Trait emotional intelligence: Behavioural validation in two studies of emotion recognition and reactivity to mood induction. European Journal of Personality, 17, 39-57.

Ployhart, R. E. (2006). The predictor response process model. In J. A. Weekley \& R. E. Ployhart (Eds.), Situational judgment tests: Theory, measurement, and application (pp. 83-105). Mahwah, NJ: Lawrence Erlbaum Associates.

Resnicow, J. E., Salovey, P., \& Repp, B. H. (2004). Is recognition of emotion in musical performance an aspect of emotional intelligence? Music Perception, 22, 145-158.

Roberts, R. D., Schulze, R., O'Brien, K., MacCann, C., Reid, J., \& Maul, A. (2006). Exploring the validity of the Mayer-Salovey-Caruso Emotional Intelligence Test (MSCEIT) with established emotions measures. Emotion, 6, 663-669.

Roberts, R. D., Zeidner, M., \& Matthews, G. (2001). Does emotional intelligence meet traditional standards for an intelligence? Some new data and conclusions. Emotion, 1, 196-231.

Roseman, I. (1984). Cognitive determinants of emotions: A structural theory. In P. Shaver (Ed.), Review of personality and social psychology: Vol. 5. Emotions, relationships, and health (pp. 11-36). Beverly Hills, CA: Sage.

Rosete, D. (2007). Does emotional intelligence play an important role in leadership effectiveness? Unpublished doctoral dissertation, University of Wollongong, Wollongong.

Rosete, D., \& Ciarrochi, J. (2005). Emotional intelligence and its relationship to workplace performance of leadership effectiveness. Leadership and Organization Development Journal, 26, 388-399.

Rubin, M. M. (1999). Emotional intelligence and its role in mitigating aggression: A correlational study of the relationship between emotional intelligence and aggression in urban adolescents. Unpublished doctoral dissertation, Immaculata College, Immaculata, Pennsylvania.

Salovey, P., \& Grewal, D. (2005). The science of emotional intelligence. Current Directions in Psychological Science, 14, 281-285.

Salovey, P., \& Mayer, J. D. (1990). Emotional intelligence. Imagination, Cognition, and Personality, 9 , $185-211$.

Saucier, G., \& Goldberg, L. R. (1998). What is beyond the Big Five? Journal of Personality, 66, 495-524.

Scherer, K. R. (1993). Studying the emotion-antecedent appraisal process: An expert system approach. Cognition and Emotion, 7, 325-355.

Schneider, T. R., Lyons, J. B., \& Williams, M. (2005). Emotional intelligence and autonomic selfperception: Emotional abilities are related to visceral acuity. Personality and Individual Differences, 39, 853-861.

Sloman, A., \& Croucher, M. (1981). Why robots will have emotions. In T. Dean (Ed.), Proceedings of the seventh international joint conference on artificial intelligence (Vol. 1). San Francisco, CA: Morgan Kaufman.

Smith, C. A., \& Ellsworth, P. C. (1985). Patterns of cognitive appraisal in emotion. Journal of Personality \& Social Psychology, 48, 813-838.

Smith, G. T. (2005). On construct validity: Issues of method and measurement. Psychological Assessment, 17, 396-408.

Solomon, R. C. (2000). The philosophy of emotions. In M. Lewis \& J. M. Haviland-Jones (Eds.), Handbook of emotions (pp. 3-15). New York: Guilford.

Sternberg, R. J. (1985). Human intelligence: The model is the message. Science, 230, 1111-1118.

Strongman, K. T. (1996). The psychology of emotion: Theories of emotion in perspective (4th ed.). Oxford, UK: John Wiley \& Sons.

TenHouten, W. D., Hoppe, J. E., Bogen, J. E., \& Walter, D. O. (1985). Alexithymia and the split brain: IV. Gottschalk-Gleser content analysis, an overview. Psychotherapy and Psychosomatics, 44, 113-121.

Tett, R. P., Fox, K. E., \& Wang, A. (2005). Development and validation of a self-report measure of emotional intelligence as a multidimensional trait domain. Personality and Social Psychology Bulletin, 31, 859-888. 
Thompson, L., \& Fine, G. A. (1999). Socially shared cognition, affect, and behavior: A review and integration. Personality and Social Psychology Review, 3, 278-302.

Thorndike, E. L. (1920). Intelligence and its use. Harper's Magazine, 140, 227-235.

Thorndike, E. L., \& Stein, S. (1937). An evaluation of the attempts to measure social intelligence. Psychological Bulletin, 34, 275-285.

Trinidad, D. R., \& Johnson, C. A. (2002). The association between emotional intelligence and early adolescent tobacco and alcohol use. Personality \& Individual Differences, 32, 95-105.

Walker, R. E., \& Foley, J. M. (1973). Social intelligence: Its history and measurement. Psychological Reports, 33, 839-864.

Watkin, C. (2000). Developing emotional intelligence. International Journal of Selection and Assessment, 8, 89-92.

Wechsler, D. (1943). Non-intellective factors in general intelligence. Journal of Abnormal \& Social Psychology, 38, 101-103.

Wechsler, D. (1997). WAIS III: Wechsler Adult Intelligence Scale (3rd ed.). San Antonio, TX: The Psychological Corporation.

Wilson, M. E., Brackett, M. A., DeRosier, M. E., \& Rivers, S. E. . (2007). Emotional Literacy in the Classroom: Kindergarten, first grade, second grade. Cary, NC: SELmedia, Inc.

Young, P. T. (1943). Emotion in man and animal: Its nature and relation to attitude and motive. New York: John Wiley \& Sons.

Zeidner, M., Matthews, G., \& Roberts, R. D. (2001). Slow down, you move too fast: Emotional intelligence remains an "elusive" intelligence. Emotion, 1, 265-275.

Zeidner, M., Roberts, R. D., \& Matthews, G. (2004). The emotional intelligence bandwagon: Too fast to live, too young to die? Psychological Inquiry, 15, 239-248. 